\title{
Olfactory taste disorder as a presenting symptom of COVID-19: a large single-center Singapore study
}

\author{
Alex C. Tham ${ }^{1}$ (1) $\cdot$ Tun-Linn Thein ${ }^{2} \cdot$ Chrisanda S. Lee ${ }^{1} \cdot$ Glorijoy S. E. $\operatorname{Tan}^{2} \cdot$ Charmaine M. Manauis $^{3} \cdot$ J. K. Siow ${ }^{1}$. \\ Y. S. Leo ${ }^{2} \cdot$ M. Y. Lim ${ }^{1}$
}

Received: 26 July 2020 / Accepted: 22 October 2020 / Published online: 7 November 2020

(c) Springer-Verlag GmbH Germany, part of Springer Nature 2020

\begin{abstract}
Purpose To investigate the prevalence and epidemiological risk factors of olfactory and/or taste disorder (OTD), in particular isolated OTD, in patients with laboratory-confirmed COVID-19 infection.

Methods We conducted a retrospective and cross-sectional study. Patients with laboratory-confirmed COVID-19 infection were recruited from the National Centre for Infectious Diseases (NCID) Singapore between 24 March 2020 and 16 April 2020. The electronic health records of these patients were accessed, and demographic data and symptoms reported (respiratory, self-reported OTD and other symptoms such as headache, myalgia and lethargy) were collected.

Results A total of 1065 patients with laboratory-confirmed COVID-19 were recruited. Overall, the prevalence of OTD was $12.6 \%$. Twelve patients (1.1\%) had isolated OTD. The top three symptoms associated with OTD were cough, fever and sore throat. The symptoms of runny nose and blocked nose were experienced by only 29.8 and $19.3 \%$ of patients, respectively. Multivariate analysis demonstrated that the female gender, presence of blocked nose and absence of fever were significantly associated with OTD (adjusted relative risks 1.77, 3.31, 0.42, respectively). All these factors were statistically significant. Conclusion Patients with COVID-19 infection can present with OTD, either in isolation or in combination with other general symptoms. Certain demographic profile, such as being female, and symptomatology such as the presence of blocked nose and absence of fever, were more likely to have OTD when infected by COVID-19. Further studies to elucidate the pathophysiology of OTD in these patients will be beneficial.
\end{abstract}

Keywords Anosmia $\cdot$ Olfactory disorder $\cdot$ Taste disoder $\cdot$ COVID-19 $\cdot$ Ageusia

\section{Introduction}

Coronavirus disease 2019 (COVID-19) was first reported in Wuhan, China in December 2019. It has since spread globally involving up to 14 million confirmed COVID-19 cases by 18 July 2020 worldwide [1]. The key to containing the spread of COVID-19 infection lies in early diagnosis and rapid isolation. Early studies reported the following

Alex C. Tham

dralextham@gmail.com

1 Department of Otorhinolaryngology, Tan Tock Seng Hospital, 11 Jalan Tan Tock Seng, Singapore 308433, Singapore

2 National Centre for Infectious Diseases, Singapore, Singapore

3 Department of Emergency Medicine, Tan Tock Seng Hospital, Singapore, Singapore symptoms, of fever, cough, dyspnea, sputum production, rhinorrhea, headache, myalgia, diarrhea and sore throat $[2$, 3]. Subsequently, there was increasing evidence of COVID19 patients presenting with olfactory and/or taste disorders (OTD) [4-7]. Patients who only have OTD following COVID-19 infection, and are otherwise well, may not be aware that they are infected, and pose a risk of transmission in the community. In response to the increasing evidence that COVID-19 patients can present with OTD, ENT UK and the British Rhinological Society issued a joint press release to increase awareness of this finding [8]. Studies have shown that the prevalence varied widely and ranged between 5.1 [4] and $85.6 \%$ [7].

In Singapore, our first case of COVID-19 patient was reported in end-January 2020. Following a local news article [9] on the 23 March 2020 which highlighted anosmia as a symptom of COVID-19, our local institution began to screen patients with anosmia for COVID-19 and included 
anosmia as a symptom in our history taking for possible COVID-19 infection. Of interest to us was this particular select group of patients who presented with isolated OTD. We defined isolated OTD as the presence of olfactory and/ or taste disorder, in the absence of any other associated symptom.

The aim of this study was to investigate the prevalence of OTD overall, in particular isolated OTD, in a large single cohort of patients in Singapore with laboratory-confirmed COVID-19 infection. A secondary aim was to identify epidemiological risk factors for OTD, and to examine if our findings were consistent with that of other studies across the world.

\section{Materials and methods}

This study was conducted in the National Centre for Infectious Diseases (NCID), Singapore's designated center for infectious disease. This was a retrospective, cross-sectional study. Ethics approval was obtained from our hospital's Institutional Review Board. Patients confirmed to have COVID-19 by SARS-CoV-2 real-time reverse transcriptasepolymerase chain reaction (RT-PCR) were eligible for inclusion in this study.

Data from the electronic health records of all newly diagnosed patients admitted to NCID, from 24 March 2020 to 16 April 2020, were collected and summarized using a standardized data collection form.

Data collected included the demographics and symptoms experienced by the patients such as respiratory, self-reported OTD and other symptoms such as headache, myalgia and lethargy. Races included Chinese, Indian, Malay, Bangladeshi, Caucasian, South East Asian and others. Patients from Thailand, Myanmar, Philippines and Indonesia were collectively classified as "South East Asians", while patients from Japan and Sri Lanka were classified under "others".

To provide clarity on how we divided our patients into groups with various combination of symptoms for comparison, we defined the terms as follows:

Definition of terms:

1. OTD is defined as the presence of olfactory and/or taste disorders with or without other associated symptoms.

2. Isolated OTD is defined as the presence of olfactory and/ or taste disorders without any other associated symptoms.

3. Non-isolated OTD is defined as the presence of olfactory and/or taste disorders with other associated symptoms.

4. Olfactory disorder is defined as the presence of olfactory disorders regardless of the presence or absence of taste disorder or associated symptoms.
5. Taste disorder is defined as the presence of olfactory disorders regardless of the presence or absence of olfactory disorder or associated symptoms.

\section{Statistical methods}

Variables analyzed included age, gender, race, presenting symptoms as well as duration of these symptoms prior to COVID-19 diagnosis. For continuous variables, the median and interquartile range were calculated and for categorical variables, the number and corresponding percentages were calculated. $p$ values for univariate analysis were calculated by Mann-Whitney $U$ or $\chi^{2}$ tests, while $p$ values for multivariate analysis were calculated by binary logistic regression for the variables specified in Table 1. Statistical significance was set at $p<0.05$ and all reported $p$ values were two tailed. Data analyses were performed by Statistical Package for the Social Sciences (SPSS) version 25.

\section{Results}

A total of 6915 patients presented to NCID for screening between 24 March 2020 and 16 April 2020. Whilst a significant proportion of our local population in Singapore were screened at our center during this period, an outbreak in foreign worker dormitories resulted in a significant proportion of the cases presenting to be young males from Bangladesh and India. We also have a sizeable population of expatriates in Singapore that were also screened at NCID during this period. This presented us with a unique opportunity to determine if there were ethnic differences in COVID-19 patients presenting with OTD.

Out of these 6915 patients, 1065 (15.4\%) patients tested positive for COVID-19 by RT-PCR and these were included in this study. There were 933 males (87.6\%) and 132 females (12.4\%) and they were aged between 28 and 42 years of age (median age of 34). The demographics and presenting symptoms of the patients are shown in Table 1.

\section{OTD outcomes}

Overall, 134 (12.6\%) COVID-19 patients presented with OTD. Two had a history of allergic rhinitis: One had a taste disorder which was associated with cough and fever while the other had only olfactory disorder with no other symptom. Although both of these patients had a history of allergic rhinitis, we included them into our study as their OTD symptoms were of a new onset. None of the 134 OTD patients had a history of sinonasal surgery. Of these 134 patients, $126(11.8 \%)$ had an olfactory disorder, $49(4.6 \%)$ had a taste disorder and 41 (3.9\%) had both olfactory and 
Table 1 Factors associated with olfactory or taste disorder among COVID-19 patients admitted to National Centre for Infectious Diseases (NCID) from 24 March 2020 to 16 April 2020

\begin{tabular}{|c|c|c|c|c|c|c|c|}
\hline \multirow[t]{2}{*}{ Factors } & \multirow[t]{2}{*}{ Total $(n=1065)$} & \multicolumn{2}{|c|}{ Smell or taste disorder } & \multicolumn{2}{|l|}{ Univariate analysis } & \multicolumn{2}{|l|}{ Multivariate analysis } \\
\hline & & Absent $(n=931)$ & Present $(n=134)$ & $\mathrm{RR}(95 \% \mathrm{CI})$ & $p$ value* & aRR $(95 \% \mathrm{CI})$ & $p$ value + \\
\hline \multicolumn{8}{|l|}{ Demographics } \\
\hline Age (years) & $34(28-42)$ & $34(28-42)$ & $34(29-41)$ & - & 0.942 & - & - \\
\hline \multicolumn{8}{|l|}{ Gender } \\
\hline Female & $132(100)$ & 97 (73.48) & $35(26.51)$ & $3.04(1.96-4.72)$ & $<0.001$ & $1.765(1.045-2.981)$ & 0.033 \\
\hline Male & $933(100)$ & $834(89.38)$ & $99(10.61)$ & (reference) & & (reference) & \\
\hline \multicolumn{8}{|l|}{ Race } \\
\hline Chinese & $154(100)$ & $119(77.27)$ & $35(22.72)$ & $2.41(1.57-3.71)$ & $<0.001$ & - & 0.175 \\
\hline Indian & $221(100)$ & $196(88.68)$ & $25(11.31)$ & - & 0.570 & - & - \\
\hline Malay & $47(100)$ & $38(80.85)$ & $9(19.14)$ & - & 0.175 & - & - \\
\hline South East Asian & $40(100)$ & $31(77.5)$ & $9(22.5)$ & - & 0.083 & - & - \\
\hline Bangladeshi & $568(100)$ & $520(91.54)$ & $48(8.45)$ & $0.44(0.30-0.64)$ & $<0.001$ & - & 0.156 \\
\hline Caucasian & $27(100)$ & $19(70.37)$ & $8(29.62)$ & $3.05(1.31-7.11)$ & 0.014 & - & 0.161 \\
\hline Other races & $8(100)$ & $8(100)$ & $0(0)$ & - & 0.606 & - & - \\
\hline \multicolumn{8}{|c|}{ Associated symptoms } \\
\hline \multicolumn{8}{|l|}{ Blocked nose } \\
\hline Yes & $69(100)$ & $46(66.66)$ & $23(33.33)$ & $3.98(2.33-6.82)$ & $<0.001$ & $3.308(1.873-5.841)$ & $<0.001$ \\
\hline No & $995(100)$ & $884(88.84)$ & $111(11.15)$ & (reference) & & & \\
\hline \multicolumn{8}{|l|}{ Runny nose } \\
\hline Yes & $193(100)$ & $156(80.82)$ & 37 (19.17) & $1.89(1.25-2.87)$ & 0.004 & - & 0.069 \\
\hline No & $871(100)$ & $774(88.86)$ & $97(11.13)$ & (reference) & & & \\
\hline \multicolumn{8}{|l|}{ Cough } \\
\hline Yes & $624(100)$ & $541(86.69)$ & $83(13.3)$ & - & 0.453 & - & - \\
\hline No & $441(100)$ & $390(88.43)$ & $51(11.56)$ & - & & & \\
\hline \multicolumn{8}{|l|}{ Sore throat } \\
\hline Yes & $388(100)$ & $332(85.56)$ & $56(14.43)$ & - & 0.179 & - & - \\
\hline No & $677(100)$ & $599(88.47)$ & $78(11.52)$ & - & & & \\
\hline \multicolumn{8}{|l|}{ Fever } \\
\hline Yes & $818(100)$ & $737(90.09)$ & $81(9.9)$ & $0.40(0.27-0.59)$ & $<0.001$ & $0.415(0.278-0.619)$ & $<0.001$ \\
\hline No & $246(100)$ & $193(78.45)$ & $53(21.54)$ & (reference) & & & \\
\hline \multicolumn{8}{|l|}{ Diarrhoea } \\
\hline Yes & $71(100)$ & $54(76.05)$ & $17(23.94)$ & $2.36(1.32-4.20)$ & 0.005 & - & 0.053 \\
\hline No & $993(100)$ & $876(88.21)$ & $117(11.78)$ & (reference) & & & \\
\hline \multicolumn{8}{|l|}{ Other symptoms } \\
\hline Yes & $442(100)$ & $397(89.81)$ & 45 (10.18) & $0.68(0.46-0.99)$ & 0.049 & - & - \\
\hline No & $622(100)$ & $533(85.69)$ & $89(14.3)$ & (reference) & & & \\
\hline
\end{tabular}

For continuous variables, median (interquartile range) were shown. For categorical variables, number (percentage) were shown

$R R$ relative risk, $a R R$ adjusted relative risk, $C I$ confidence interval

${ }^{*} p$ values for univariate analysis were calculated by Mann-Whitney $U$ or $\chi^{2}$ tests

${ }^{+} p$ values for multivariate analysis were calculated by binary logistic regression

- Not included in multivariate model

Bold values indicate that the statistically significant

taste disorders. The median duration of olfactory and taste disorders at presentation were 3 and 2 days, respectively.

Comparing patients with OTD to patients without OTD, univariate analysis demonstrated that females were three times more likely to have OTD as compared to males.
Univariate analysis also demonstrated that across all races, Caucasians and Chinese patients were $3.05(p=0.014)$ and $2.41(p<0.001)$ times more likely to present with OTD. These differences were all statistically significant. For associated symptoms, patients with concomitant blocked nose, 
runny nose and diarrhoea were more likely to have OTD, while patients with fever and other associated symptoms were less likely to have smell or taste disorders $(p<0.05)$ (Table 1). To further analyze independent risk factors for OTD, a multivariate analysis was done which showed that only female gender, presence of blocked nose and absence of fever were significantly associated with OTD (adjusted relative risks $1.77,3.31,0.42$, respectively) (Table 1 ).

Amongst the 134 patients with OTD, 12 (1.1\%) had isolated OTD, while 122 patients had associated symptoms such as respiratory, gastrointestinal symptoms and fever. We compared the 12 isolated OTD patients to the other 122 OTD patients in terms of age, gender, race and duration of OTD symptoms prior to COVID19 diagnosis. Univariate analysis showed that for age, isolated OTD patients tended to be younger ( 30 vs. $34, p=0.044$ ) and this was statistically significant. For gender and race, a higher proportion of females (11.8 vs. 9.8\%, $p=0.733$ ), South East Asian and Chinese patients $(22.2,17.1 \%, p=0.176)$ had isolated OTD, respectively.

For the OTD patients with other associated symptoms (non-isolated OTD), the top three symptoms were cough, fever and sore throat (Table 2). Interestingly, the symptoms of runny nose and blocked nose were experienced by only 30.3 and $18.9 \%$ of the patients, respectively. A summary of the characteristics of the 12 patients with isolated OTD, including the number of days of anosmia prior to diagnosis is shown in Table 3.

\section{Olfactory disorder outcomes}

Out of the 1065 COVID-19-positive patients, 126 (11.8\%) patients had an olfactory disorder. Of these, 126 patients, 41 patients had concomitant taste disorder as well. Comparing these patients with olfactory disorder to those who had absent olfactory symptoms, univariate analysis showed that being female, Caucasian and subjects having the symptoms of blocked nose, runny nose and diarrhea were more likely to have an olfactory disorder. On the contrary, having a fever makes one less likely to have an olfactory disorder. These differences are statistically significant (Table 4).

\section{Taste disorder outcomes}

Out of the 1065 COVID-19-positive patients, 49 (4.6\%) patients had a taste disorder. Of these 49 patients, 8 patients
Table 2 Factors associated with isolated olfactory and taste disorder among COVID-19 patients admitted to National Centre for Infectious Diseases (NCID) from 24 March 2020 to 16 April 2020

\begin{tabular}{|c|c|c|c|c|}
\hline Factors & Total OTD $(n=134)$ & $\begin{array}{l}\text { Non-isolated } \\
\text { OTD }(n=122)\end{array}$ & Isolated OTD $(n=12)$ & $p$ value \\
\hline \multicolumn{5}{|l|}{ Demographics } \\
\hline Age (years) & $34(29-41)$ & $34(29-43)$ & $30(25-37.75)$ & 0.046 \\
\hline \multicolumn{5}{|l|}{ Gender } \\
\hline Female & $35(100)$ & $31(88.57)$ & $4(11.42)$ & \multirow[t]{2}{*}{0.511} \\
\hline Male & 99 (100) & $91(91.91)$ & $8(8.08)$ & \\
\hline \multicolumn{5}{|l|}{ Race } \\
\hline Chinese & $35(100)$ & $29(82.85)$ & $6(17.14)$ & \multirow[t]{7}{*}{0.132} \\
\hline Indian & $25(100)$ & $23(92)$ & $2(8)$ & \\
\hline Malay & $9(100)$ & $8(88.88)$ & $1(11.11)$ & \\
\hline South East Asian & $9(100)$ & $7(77.77)$ & $2(22.22)$ & \\
\hline Bangladeshi & $48(100)$ & $47(97.91)$ & $1(2.08)$ & \\
\hline Caucasian & $8(100)$ & $8(100)$ & $0(0)$ & \\
\hline Others & $0(0)$ & $0(0)$ & $0(0)$ & \\
\hline \multicolumn{5}{|l|}{ Small disorder } \\
\hline Yes & $126(100)$ & $114(90.47)$ & $12(9.52)$ & \multirow[t]{2}{*}{$>0.999$} \\
\hline No & $8(100)$ & $8(100)$ & $0(0)$ & \\
\hline Taste disorder & $3(2-5)$ & $3(2-5)$ & $3.5(1.25-5)$ & 0.631 \\
\hline \multicolumn{5}{|l|}{ Small disorder duration, days } \\
\hline Yes & 49 (100) & $42(85.71)$ & $7(14.28)$ & \multirow[t]{2}{*}{0.122} \\
\hline No & 85 (100) & $80(94.11)$ & $5(5.88)$ & \\
\hline Taste disorder duration, days & $2(1-4)$ & $2(1-4)$ & $2(1-5)$ & 0.016 \\
\hline
\end{tabular}

For continuous variables, median (interquartile range) were shown. For categorical variables, number (percentage) were shown

OTD olfactory and taste disorder

Bold values indicate that the statistically significant 
Table 3 Summary of demographic profile and symptoms of the patients with isolated OTD

\begin{tabular}{lllllll}
\hline Patient no & Age & Gender & Race & Occupation & Comorbidities & $\begin{array}{c}\text { Duration of OTD } \\
\text { prior to diagnosis } \\
\text { (days) }\end{array}$ \\
\hline 1 & & & & Asthma & 1 \\
2 & 26 & Female & Chinese & Doctor & Nil & 1 \\
3 & 51 & Male & Chinese & Salesman & Nil & 1 \\
4 & 31 & Male & Indian & Construction worker & Hyperlipidaemia, & 2 \\
5 & 25 & Female & Chinese & Doctor & Nil & 2 \\
6 & 23 & Male & Indian & Student & Nil & 3 \\
7 & 30 & Male & South East Asian & Construction worker & Nil & 4 \\
8 & 31 & Male & Chinese & Financial Planner & Nil & 4 \\
9 & 25 & Female & Malay & Executive & Asthma & 4 \\
10 & 22 & Female & Chinese & Student & Nil & 5 \\
11 & 41 & Male & South East Asian & Salesman & Nil & Nil \\
\hline 12 & 40 & Male & Chinese & Teacher & Plumber & \\
\hline
\end{tabular}

had no concomitant olfactory disorder and all of them had associated symptoms such as respiratory or gastrointestinal symptoms. Comparing these patients with a taste disorder to those who had absent taste symptoms, univariate analysis showed that being female, Caucasian and subjects having the symptoms of blocked nose and runny nose were more likely to have a taste disorder. However, having a fever made one less likely to have a taste disorder. These differences are statistically significant (Table 5).

\section{Discussion}

Post-viral olfactory dysfunction caused by rhinovirus, coronavirus, parainfluenza virus and Epstein-Barr virus has previously been described [10-12]. Zayet et al. [12] compared the clinical features of COVID-19 to influenza and found that there was a higher incidence of anosmia (53 vs. 17\%) and dysgeusia (49 vs. 20\%) in patients with COVID-19. Interestingly, the authors found that the mean duration of anosmia was shorter in influenza than in COVID-19, with 3 and 7 days, respectively.

Our study found that the prevalence of OTD (12.6\%) amongst our COVID-19 patients to be on the lower end of the spectrum compared to the multiple studies done, which ranged between 5.1 and $85.6 \%$ [4-7]. In our study, we found that OTD was more common in female patients and across all races, we found that Caucasians were more most at risk of having OTD. These findings are similar to studies found in the literature [5, 7, 13].

The pathophysiology of OTD in COVID-19 is still under debate and several mechanisms have been proposed. First, OTD could result from an obstruction of the olfactory clefts [14], thereby preventing the activation of sensory neurons in the olfactory epithelium by the odorants. Our study found that the symptoms of blocked nose and runny nose portend a 3.98 and 1.89 relative risks of having OTD on univariate analysis ( $p<0.001$ and $p=0.004$, respectively). The symptom of blocked nose, on multivariate analysis, portends a 3.31 adjusted relative risk of OTD $(p>0.001)$. This finding supports this proposed mechanism of obstruction in the olfactory cleft in these patients. However, we note that these symptoms of blocked nose and runny nose were only present in up to $30 \%$ of our patients with OTD, suggesting that whilst blocked nose can contribute to OTD, the majority of our patients' OTD symptoms must be due to other nonobstructive causes. Chung et al.'s [15] study demonstrated that half of their patients with OTD had patent olfactory clefts on imaging and this lends further support to nonobstructive causes of OTD.

An alternative mechanism proposed was that the inflammatory cytokine environment in the nasal cavity could potentially affect the olfactory neuronal function, as in chronic rhinosinusitis, as found by $\mathrm{Wu}$ et al. [16]. In their study, they found that elevated levels of inflammatory cytokines were associated with reduced olfactory identification scores in patients with chronic rhinosinusitis. However, Chung et al. [15] again found that only $17 \%$ of their patients with OTD had rhinorrhea or nasal congestion and minimal inflammatory infiltrates as seen in their nasal biopsy specimens. This would suggest that local inflammation is at best a contributing factor but not the sole factor. Similarly, as mentioned earlier, we found in our study that the majority of our OTD patients had no rhinorrhea or nasal obstruction.

Lastly, it was proposed that OTD could result not from a conductive problem but rather from a sensorineural etiology, where there is a direct invasion of the olfactory neurons by SARS-CoV-2. It has been shown that SARS-CoV-2 
Table 4 Factors associated with olfactory disorder among COVID-19 patients admitted to National Centre for Infectious Diseases (NCID) from 24 March 2020 to 16 April 2020

\begin{tabular}{|c|c|c|c|c|}
\hline \multirow[t]{2}{*}{ Factors } & \multirow[t]{2}{*}{ Total $(n=1065)$} & \multicolumn{2}{|l|}{ Olfactory disorder } & \multirow[t]{2}{*}{$\mathrm{p}$ value } \\
\hline & & Absent $(n=939)$ & Present $(n=126)$ & \\
\hline \multicolumn{5}{|l|}{ Demographics } \\
\hline Age (years) & $34(28-42)$ & $34(28-42)$ & $34(29-41)$ & 0.933 \\
\hline \multicolumn{5}{|l|}{ Gender } \\
\hline Female & $132(100)$ & $98(74.24)$ & $34(25.75)$ & \multirow[t]{2}{*}{$<0.001$} \\
\hline Male & $933(100)$ & $841(90.13)$ & $92(9.86)$ & \\
\hline \multicolumn{4}{|l|}{ Race } & \multirow[t]{8}{*}{$<0.001$} \\
\hline Chinese & $154(100)$ & $119(77.27)$ & $35(22.72)$ & \\
\hline Indian & $221(100)$ & $199(90.04)$ & $22(9.95)$ & \\
\hline Malay & 47 (100) & $39(82.97)$ & $8(17.02)$ & \\
\hline South East Asian & $40(100)$ & $31(77.5)$ & $9(22.5)$ & \\
\hline Bangladeshi & $568(100)$ & $524(92.25)$ & $44(7.74)$ & \\
\hline Caucasian & $27(100)$ & $19(70.37)$ & $8(29.62)$ & \\
\hline Others & $8(100)$ & $8(100)$ & $0(0)$ & \\
\hline \multicolumn{5}{|l|}{ Associated symptoms } \\
\hline \multicolumn{5}{|l|}{ Blocked nose } \\
\hline Yes & $69(100)$ & $47(68.11)$ & $22(31.88)$ & \multirow[t]{2}{*}{$<0.001$} \\
\hline No & $995(100)$ & $891(89.54)$ & $104(10.45)$ & \\
\hline \multicolumn{5}{|l|}{ Runny nose } \\
\hline Yes & $193(100)$ & $159(82.38)$ & $34(17.61)$ & \multirow[t]{2}{*}{0.009} \\
\hline No & $871(100)$ & 779 (89.43) & $92(10.56)$ & \\
\hline \multicolumn{5}{|l|}{ Cough } \\
\hline Yes & $624(100)$ & $546(87.5)$ & $78(12.5)$ & \multirow[t]{2}{*}{0.442} \\
\hline No & $441(100)$ & $393(89.11)$ & $48(10.88)$ & \\
\hline \multicolumn{5}{|l|}{ Sore throat } \\
\hline Yes & $388(100)$ & $336(86.59)$ & $52(13.4)$ & \multirow[t]{2}{*}{0.238} \\
\hline No & $677(100)$ & $603(89.06)$ & $74(10.93)$ & \\
\hline \multicolumn{5}{|l|}{ Fever } \\
\hline Yes & $818(100)$ & $743(90.83)$ & $75(9.16)$ & \multirow[t]{2}{*}{$<0.001$} \\
\hline No & $246(100)$ & $195(79.26)$ & $51(20.73)$ & \\
\hline \multicolumn{5}{|l|}{ Diarrhoea } \\
\hline Yes & $71(100)$ & 55 (77.46) & $16(22.53)$ & \multirow[t]{2}{*}{0.007} \\
\hline No & 993 (100) & $883(88.92)$ & $110(11.07)$ & \\
\hline \multicolumn{5}{|l|}{ Other symptoms } \\
\hline Yes & $442(100)$ & 399 (90.27) & $43(9.72)$ & \multirow[t]{2}{*}{0.083} \\
\hline No & $622(100)$ & $539(86.65)$ & $83(13.34)$ & \\
\hline
\end{tabular}

Frequency (\%) shown for categorical variables and median (interquartile range) shown for continuous variables

Bold values indicate that the statistically significant utilizes its S1 spike glycoprotein for attachment to and infect host target cells [17]. The angiotensin-converting enzyme-2 (ACE2) serves as cell surface receptor for the virus where it binds to the $\mathrm{S} 1$ spike glycoprotein. ACE2 is required for cellular entry of virus via endocytosis. A second protein, the transmembrane protease serine 2 (TMPRSS2), is a protease that resides in the endosomal compartment. TMPRSS2 is required for the priming and cleavage of the $\mathrm{S} 1$ spike glycoprotein. Subsequently, this allows fusion of the viral envelope with the endosomal compartment with the introduction of the viral contents, including its genetic material, into the cytoplasm of the host target cell [18]. Both ACE2 and TMPRSS2 genes are found in the supporting cells of the human neuroepithelium, making them viable targets for SARS-CoV-2 infection. Damage to the olfactory bulb with the development of microbleeding and oedema, as seen on magnetic resonance imaging, have been reported in COVID19 patients with OTD $[19,20]$. In contrast, human influenza A virus binds to $\alpha 2,6$-linked sialic acid receptors, which are widely expressed in the respiratory tract [21]. Differences 
Table 5 Factors associated with taste disorder among COVID-

19 patients admitted to National Centre for Infectious Diseases (NCID) from 24 March 2020 to 16 April 2020

\begin{tabular}{|c|c|c|c|c|}
\hline \multirow[t]{2}{*}{ Factors } & \multirow[t]{2}{*}{ Total $(n=1065)$} & \multicolumn{2}{|l|}{ Taste disorder } & \multirow[t]{2}{*}{$p$ value } \\
\hline & & Absent $(n=1016)$ & Present $(n=49)$ & \\
\hline \multicolumn{5}{|l|}{ Demographics } \\
\hline Age (years) & $34(28-42$ & $34(28-42)$ & $31(26.5-41.5)$ & 0.293 \\
\hline \multicolumn{5}{|l|}{ Gender } \\
\hline Female & $132(100)$ & $113(85.6)$ & $19(14.39)$ & $<0.001$ \\
\hline Male & $933(100)$ & $903(96.78)$ & $30(3.21)$ & \\
\hline Race & & & & $<0.001$ \\
\hline Chinese & $154(100)$ & $140(90.9)$ & $14(9.09)$ & \\
\hline Indian & $221(100)$ & $214(96.83)$ & $7(3.16)$ & \\
\hline Malay & $47(100)$ & $41(87.23)$ & $6(12.76)$ & \\
\hline South East Asian & $40(100)$ & $36(90)$ & $4(10)$ & \\
\hline Bangladeshi & $568(100)$ & $555(97.71)$ & $13(2.28)$ & \\
\hline Caucasian & $27(100)$ & $22(81.48)$ & $5(18.51)$ & \\
\hline Others & $8(100)$ & $8(100)$ & $0(0)$ & \\
\hline \multicolumn{5}{|c|}{ Associataed symptoms } \\
\hline \multicolumn{5}{|l|}{ Blocked nose } \\
\hline Yes & $69(100)$ & $58(84.05)$ & $11(15.94)$ & $<0.001$ \\
\hline No & $995(100)$ & $957(96.18)$ & $38(3.81)$ & \\
\hline \multicolumn{5}{|l|}{ Runny nose } \\
\hline Yes & $193(100)$ & $178(92.22)$ & $15(7.77)$ & 0.034 \\
\hline No & $871(100)$ & $837(96.09)$ & $34(3.9)$ & \\
\hline \multicolumn{5}{|l|}{ Cough } \\
\hline Yes & $624(100)$ & $597(95.67)$ & $27(4.32)$ & 0.657 \\
\hline No & $441(100)$ & $419(95.01)$ & $22(4.98)$ & \\
\hline \multicolumn{5}{|l|}{ Sore throat } \\
\hline Yes & $388(100)$ & $373(96.13)$ & $15(3.86)$ & 0.449 \\
\hline No & $677(100)$ & $643(94.97)$ & $34(5.02)$ & \\
\hline \multicolumn{5}{|l|}{ Fever } \\
\hline Yes & $818(100)$ & 791 (96.69) & $27(3.3)$ & 0.001 \\
\hline No & $246(100)$ & 224 (91.05) & $22(8.94)$ & \\
\hline \multicolumn{5}{|l|}{ Diarrhoea } \\
\hline Yes & $71(100)$ & 66 (92.95) & $5(7.04)$ & 0.370 \\
\hline No & $993(100)$ & 949 (95.56) & $44(4.43)$ & \\
\hline \multicolumn{5}{|l|}{ Other symptoms } \\
\hline Yes & $442(100)$ & $428(96.83)$ & $14(3.16)$ & 0.074 \\
\hline No & $622(100)$ & 587 (94.37) & $35(5.62)$ & \\
\hline
\end{tabular}

Frequency (\%) shown for categorical variables and median (interquartile range) shown for continuous variables

Bold values indicate that the statistically significant in the types of receptors for SARS-CoV2 and influenza A could possibly explain the difference in the prevalence and severity of OTD symptoms between the 2 infections, where it is less common for influenza patients to have anosmia and dysgeusia [12].

Our study also demonstrated that other than blocked nose, being female was an independent risk factor. This is consistent with other studies $[5,7,22]$. Gender-related differences in the inflammatory reaction process have been well studied [23]. It was proposed that this difference could have resulted in a higher proportion of female patients having OTD [7]. However, Lefévre et al. [23] found in their study that there was a higher cytokine inflammatory response in men than women. If gender-related differences in the inflammatory reaction were to be at play, males should be more at risk of OTD, which has not been shown to be the case in multiple studies, including ours. In our study, this predilection for females was found to still be significant on multivariate analysis (adjusted relative risk 1.77, $p=0.033$ ), thus gender difference via another mechanism must be at play. 
Interestingly, we found that the absence of fever was associated with OTD $(p<0.001)$. This implies an inverse relationship between the body's systemic pyrogenic response to the virus and developing OTD. The reason for this is unclear at this stage, but it is possible that patients with fever are systemically unwell with malaise and in these patients, OTD symptoms though present, become a secondary complaint.

In our study, across all races, we found that Caucasians had the highest prevalence of OTD on univariate analysis. In fact, they were 3.05 times more at risk of having OTD. This apparent racial difference in the prevalence of OTD is not a new finding. A systematic review and meta-analysis by von Bartheld et al. [13] found significant racial differences, in terms of OTD, between countries with a majority of East Asians and countries with a majority of Caucasians. They found that Caucasians were at 3-, 6- and threefold higher risk for olfactory, taste and olfactory and/or taste disorders, respectively. This racial difference could be attributed to the racial differences in the frequency of variants of ACE2 which have been found to be genetically determined [24]. With the variable frequency of ACE2 variants, this would have an effect on the binding and entry of SARS-CoV-2 into the host cells and thereby the prevalence of OTD. Interestingly, this propensity of OTD affecting Caucasians disappeared on multivariate analysis in our study. It remains to be seen if ethnic differences can be demonstrated to be an independent risk factor on multivariate analysis in a single large cohort study, rather than by indirect comparison through systemic review and meta-analysis.

Amongst our 134 patients with OTD, 12 (9\%) had isolated OTD. This is similar to the rate reported by Wee et al. [25]. Other studies reported a prevalence ranging between 16.7 and $26.6 \%[22,26]$. An interesting finding amongst these 12 patients was that, of those who presented early within the first 2 days of onset of OTD, 2 were medical doctors (Table 3). Amongst the remaining 10 patients, patient 11, a 40-year-old male teacher, revealed that he had brushed aside his OTD symptom for the preceding 7 days and only presented for screening upon reading the local news article on OTD as a presenting symptom of COVID-19. This highlights the importance of public education and awareness, especially during a pandemic. The medical doctors, being healthcare workers, understandably, would be well aware of all the symptoms associated with SARS-CoV-2 infection. On the other hand, a lay person in the community will have to rely on expedient and reliable public education over the media to stay up to date with the rapidly evolving situation in the COVID-19 pandemic. This highlights the importance of systematic public education to reduce transmission of the virus.

We acknowledge several limitations to our study. First, the OTD symptoms were self-reported. Ideally, the OTD symptoms should be corroborated with psychophysical tests to verify the nature of the patient's reported symptoms of OTD but this would have been difficult to do in such a large number of patients in our cohort. In addition, it would have been ideal to have incorporated imaging to assess the patency of the olfactory clefts and nasal cavity. These evidently were the drawbacks of a large retrospective study, such as ours.

Second, our patient cohort is made up mostly of young male patients. However, this is unavoidable as this is a result of a situation peculiar to Singapore where there is a much higher prevalence of SARS-CoV-2 infection in the dormitories where our foreign workers reside as compared to the Singapore community at large. This has resulted in more than half of our study cohort to be made up of young Bangladeshi males. However, we believe that the representation of different ethnicities gave us a unique opportunity to compare differences between different ethnic groups in a single large cohort study. In this study, we employed multivariate analysis to eliminate any statistical bias resulting from the disproportionate representation.

Nevertheless, despite our limitations, we believe that we have found some important findings. In our study, we have found that the demographic profile of female gender and symptomatology (presence of blocked nose and absence of fever) at higher risk of developing OTD. We have also found that isolated OTD can be a manifestation of COVID-19 infection. Although this was only a small group of patients, the diagnosis of COVID-19 could be delayed as they are generally well, and they might be unaware that OTD could be a presenting symptom of COVID-19. There might be more patients with isolated OTD due to COVID-19 infection than our reported prevalence of $1.1 \%$. The importance of public education in a pandemic cannot be overemphasized. Educating the public regarding these symptoms, especially for patients of the at-risk demographic profiles, may improve our pickup rate of COVID-19 infections and reduce unexplained community infections with no apparent links to infected cases. With updated scientific data, authorities will then be able to better modify healthcare policies and strategies for public education accordingly.

\section{Conclusion}

Our study demonstrates that patients infected with SARSCoV-2 can present with OTD, either in isolation or in combination with other symptoms such as respiratory or gastrointestinal symptoms. Our study is unique in that this is a large study of laboratory confirmed COVID-19-positive patients, and the profile of the population examined enabled comparison between several ethnic groups. Findings from this study demonstrates that the demographic profile of being female, and patients with symptomatology such 
as the presence of blocked nose and absence of fever, are more likely to have OTD when infected by SARS-CoV-2. Further studies to elucidate the pathophysiology of OTD in these patients will be beneficial. Public awareness of subtle, uncommon and non-life-threatening symptoms of COVID19 such as OTD may be crucial to breaking the transmission of unlinked community cases.

Acknowledgements We would like to acknowledge Miss Agnes Chew, for her assistance in data collection.

\section{Compliance with ethical standards}

Conflict of interest None of the authors has a conflict of interest to declare.

Ethical approval Ethical approval (Reference: 2020/00446) was given by our hospital's Institutional Review Board, National Healthcare Group Domain Specific Review Board, Singapore.

Informed consent A formal informed consent procedure was waived due to the retrospective nature of this study.

\section{References}

1. World Health Organization (2020) Coronavirus disease (COVID19) Situation Report-181. https://www.who.int/docs/default-sourc e/coronaviruse/situation-reports/20200719-covid-19-sitrep-181. pdf?sfvrsn $=823524962$ 2. Accessed 20 July 2020

2. Chen N, Zhou M, Dong X, Qu J, Gong F, Han Y, Qiu Y, Wang J, Liu Y, Wei Y, Xia J, Yu T, Zhang X, Zhang L (2020) Epidemiological and clinical characteristics of 99 cases of 2019 novel coronavirus pneumonia in Wuhan, China: a descriptive study. Lancet 395(10223):507-513. https://doi.org/10.1016/S0140 -6736(20)30211-7

3. Young BE, Ong SWX, Kalimuddin S, Low JG, Tan SY, Loh J, Ng OT, Marimuthu K, Ang LW, Mak TM, Lau SK, Anderson DE, Chan KS, Tan TY, Ng TY, Cui L, Said Z, Kurupatham L, Chen MI, Chan M, Vasoo S, Wang LF, Tan BH, Lin RTP, Lee VJM, Leo YS, Lye DC, Singapore Novel Coronavirus Outbreak Research T (2020) Epidemiologic Features and Clinical Course of Patients Infected With SARS-CoV-2 in Singapore. JAMA. https ://doi.org/10.1001/jama.2020.3204

4. Mao L, Jin H, Wang M, Hu Y, Chen S, He Q, Chang J, Hong C, Zhou Y, Wang D, Miao X, Li Y, Hu B (2020) Neurologic manifestations of hospitalized patients with coronavirus disease 2019 in Wuhan, China. JAMA Neurol. https://doi.org/10.1001/jaman eurol.2020.1127

5. Giacomelli A, Pezzati L, Conti F, Bernacchia D, Siano M, Oreni L, Rusconi S, Gervasoni C, Ridolfo AL, Rizzardini G, Antinori S, Galli M (2020) Self-reported olfactory and taste disorders in SARS-CoV-2 patients: a cross-sectional study. Clin Infect Dis. https://doi.org/10.1093/cid/ciaa330

6. Gilani S, Roditi R, Naraghi M (2020) COVID-19 and anosmia in Tehran. Iran Med Hypotheses 141:109757. https://doi. org/10.1016/j.mehy.2020.109757

7. Lechien JR, Chiesa-Estomba CM, De Siati DR, Horoi M, Le Bon SD, Rodriguez A, Dequanter D, Blecic S, El Afia F, Distinguin L, Chekkoury-Idrissi Y, Hans S, Delgado IL, Calvo-Henriquez C, Lavigne P, Falanga C, Barillari MR, Cammaroto G, Khalife M, Leich P, Souchay C, Rossi C, Journe F, Hsieh J, Edjlali M,
Carlier R, Ris L, Lovato A, De Filippis C, Coppee F, Fakhry N, Ayad T, Saussez S (2020) Olfactory and gustatory dysfunctions as a clinical presentation of mild-to-moderate forms of the coronavirus disease (COVID-19): a multicenter European study. Eur Arch Otorhinolaryngol. https://doi.org/10.1007/s00405-020-05965-1

8. Claire Hopkins NK (2020) Loss of sense of smell as marker of COVID-19 infection. https://www.entuk.org/loss-sense-smell -marker-covid-19-infection-0. Accessed 23 June 2020

9. Today (2020) Lost sense of smell may be peculiar clue to coronavirus infection. https://www.todayonline.com/world/lost-sense -smell-may-be-peculiar-clue-coronavirus-infection. Accessed 23 June 2020

10. Suzuki M, Saito K, Min WP, Vladau C, Toida K, Itoh H, Murakami S (2007) Identification of viruses in patients with postviral olfactory dysfunction. Laryngoscope 117(2):272-277. https ://doi.org/10.1097/01.mlg.0000249922.37381.1e

11. Hwang CS (2006) Olfactory neuropathy in severe acute respiratory syndrome: report of A case. Acta Neurol Taiwan 15(1):26-28

12. Zayet S, Kadiane-Oussou NJ, Lepiller Q, Zahra H, Royer PY, Toko L, Gendrin V, Klopfenstein T (2020) Clinical features of COVID-19 and influenza: a comparative study on Nord FrancheComte cluster. Microbes Infect. https://doi.org/10.1016/j.micin f.2020.05.016

13. von Bartheld CS, Hagen MM, Butowt R (2020) Prevalence of chemosensory dysfunction in COVID-19 Patients: a systematic review and meta-analysis reveals significant ethnic differences. medRxiv. https://doi.org/10.1101/2020.06.15.20132134

14. Eliezer M, Hautefort C, Hamel AL, Verillaud B, Herman P, Houdart E, Eloit C (2020) Sudden and complete olfactory loss function as a possible symptom of COVID-19. JAMA Otolaryngol Head Neck Surg. https://doi.org/10.1001/jamaoto.2020.0832

15. Chung TW, Sridhar S, Zhang AJ, Chan KH, Li HL, Wong FK, Ng MY, Tsang RK, Lee AC, Fan Z, Ho RS, Luk SY, Kan WK, Lam SH, Wu AK, Leung SM, Chan WM, Ng PY, To KK, Cheng VC, Lung KC, Hung IF, Yuen KY (2020) Olfactory dysfunction in coronavirus disease 2019 patients: observational cohort study and systematic review. Open Forum Infect Dis 7(6):199. https:// doi.org/10.1093/ofid/ofaa199

16. Wu J, Chandra RK, Li P, Hull BP, Turner JH (2018) Olfactory and middle meatal cytokine levels correlate with olfactory function in chronic rhinosinusitis. Laryngoscope 128(9):E304-E310. https:// doi.org/10.1002/lary.27112

17. Walls AC, Park YJ, Tortorici MA, Wall A, McGuire AT, Veesler D (2020) Structure, function, and antigenicity of the SARSCoV-2 spike glycoprotein. Cell 181(2):281-292. https://doi. org/10.1016/j.cell.2020.02.058

18. Hoffmann M, Kleine-Weber H, Schroeder S, Kruger N, Herrler T, Erichsen S, Schiergens TS, Herrler G, Wu NH, Nitsche A, Muller MA, Drosten C, Pohlmann S (2020) SARS-CoV-2 cell entry depends on ACE2 and TMPRSS2 and is blocked by a clinically proven protease inhibitor. Cell 181(2):271-280. https://doi. org/10.1016/j.cell.2020.02.052

19. Aragao M, Leal MC, Cartaxo Filho OQ, Fonseca TM, Valenca MM (2020) Anosmia in COVID-19 associated with injury to the olfactory bulbs evident on MRI. AJNR Am J Neuroradiol. https ://doi.org/10.3174/ajnr.A6675

20. Laurendon T, Radulesco T, Mugnier J, Gerault M, Chagnaud C, El Ahmadi AA, Varoquaux A (2020) Bilateral transient olfactory bulbs edema during COVID-19-related anosmia. Neurology. https ://doi.org/10.1212/WNL.0000000000009850

21. Kumlin U, Olofsson S, Dimock K, Arnberg N (2008) Sialic acid tissue distribution and influenza virus tropism. Influenza Other Respir Viruses 2(5):147-154. https://doi.org/10.111 1/j.1750-2659.2008.00051.x

22. Hopkins C, Surda P, Whitehead E, Kumar BN (2020) Early recovery following new onset anosmia during the COVID-19 
pandemic - an observational cohort study. J Otolaryngol Head Neck Surg 49(1):26. https://doi.org/10.1186/s40463-020-00423-8

23. Lefevre N, Corazza F, Valsamis J, Delbaere A, De Maertelaer V, Duchateau J, Casimir G (2019) The number of X chromosomes influences inflammatory cytokine production following toll-like receptor stimulation. Front Immunol 10:1052. https:// doi.org/10.3389/fimmu.2019.01052

24. Cao Y, Li L, Feng Z, Wan S, Huang P, Sun X, Wen F, Huang $X$, Ning G, Wang W (2020) Comparative genetic analysis of the novel coronavirus (2019-nCoV/SARS-CoV-2) receptor ACE2 in different populations. Cell Discov 6:11. https://doi.org/10.1038/ s41421-020-0147-1

25. Wee LE, Chan YFZ, Teo NWY, Cherng BPZ, Thien SY, Wong HM, Wijaya L, Toh ST, Tan TT (2020) The role of self-reported olfactory and gustatory dysfunction as a screening criterion for suspected COVID-19. Eur Arch Otorhinolaryngol. https://doi. org/10.1007/s00405-020-05999-5

26. Kaye R, Chang CWD, Kazahaya K, Brereton J, Denneny JC III (2020) COVID-19 anosmia reporting tool: initial findings. Otolaryngol Head Neck Surg. https://doi.org/10.1177/019459982092299 2

Publisher's Note Springer Nature remains neutral with regard to jurisdictional claims in published maps and institutional affiliations. 